\title{
"Saya Takut Tidak Bisa Jadi Guru yang Baik": Refleksi Kecemasan Mengajar Mahasiswa Calon Guru
}

\author{
Sitti Nurfaidah ${ }^{1}$, St. Suraidah A. D. Datu ${ }^{2}$, Amsar $^{3}$ \\ 1Fakultas Tarbiyah dan Ilmu Keguruan Institut Agama Islam Negeri Kendari \\ ${ }^{2,3}$ SMA Negeri 4 Kendari \\ Corresponding Author: sitti.nurfaidah.haddad@gmail.com
}

\begin{abstract}
This case study aims to examine and discuss preservice teachers' anxiety in facing real classrooms during their field teaching program. This study was exploratory and interpretive in nature. Data were collected from ten student teachers' reflective teaching journal and in-depth interview. The participants were assigned to teach Islamic Religious subject at one of state high schools in Kota Kendari, Indonesia. Results content and level of participants' reflection analysis indicate that the participants' anxiety was immense at their first day at the school. Their overwhelmingly negative emotion, however, was gradually reduced as the program proceeded when they were involved in school observation and administrative tasks as well as socializing and adapting to new educational environment at the first two weeks. Upon teaching the real classroom for the first time, they were filled with more apprehension; the fear of not being able to deliver material well and not being able to be a good teacher were amongst their worries. This preliminary study implies the need for further and comprehensive empirical study on psychological factors the student teachers might encounter during their field teaching program and how this concern is accommodated by the teacher education program.
\end{abstract}

Keywords: anxiety; field teaching program; preservice teacher; reflection; reflective teaching

\begin{abstract}
Abstrak
Kajian studi kasus ini dilakukan untuk memahami dan memberi gambaran pengalaman nyata mahasiswa calon guru terkait kecemasan yang mereka hadapi ketika turun langsung ke lapangan untuk mengajar di kelas nyata. Data diambil dari catatan refleksi pengalaman mengajar sepuluh mahasiswa calon guru Pendidikan Agama Islam yang melaksanakan program Praktek Pengalaman Lapangan (PPL) di salah satu sekolah menengah atas negeri di Kota Kendari. Data refleksi tersebut ditriangulasi dengan wawancara mendalam. Hasil analisis isi dan kedalaman refleksi partisipan menunjukkan bahwa mahasiswa calon guru mengalami kecemasan di hari pertama mereka berada di lokasi PPL. Akan tetapi hal tersebut berkurang sejalan dengan keterlibatan mereka dengan tugas observasi dan administrasi sekolah serta keinginan mereka untuk bersosialisasi dan beradaptasi di lingkungan baru. Kecemasan lain yang mereka alami adalah saat mereka dihadapkan dengan tugas mengajar untuk pertama kali di hadapan siswa. Beragam alasan terungkap terkait kecemasan saat mengajar di depan kelas nyata untuk pertama kalinya, seperti cemas tidak mampu menyampaikan materi dengan baik dan cemas tidak bisa menjadi guru yang baik. Studi pendahuluan ini mengindikasikan perlunya kajian yang lebih mendalam dan komprehensif terkait faktor psikologis yang dihadapi mahasiswa calon guru saat mereka melaksanakan program PPL dan bagaimana langkah yang harus ditempuh oleh pihak pengelola program pendidikan dan keguruan.
\end{abstract}


Keywords: kecemasan; mahasiswa calon guru; pengajaran reflektif; praktek pengalaman lapangan; refleksi

\section{A. Pendahuluan}

Penelitian terhadap kecemasan yang dialami oleh para calon guru saat ditugaskan untuk mengajar di kelas nyata telah menjadi pusat perhatian peneliti bidang pendidikan ${ }^{1}$. Dalam rentang waktu tiga dekade terakhir telah banyak hasil penelitian yang disajikan terkait kecemasan calon guru baik saat mengajar di kelas Microteaching ${ }^{2}$, maupun saat mengajar di program praktikum atau Praktek Pengalaman Lapangan (PPL) ${ }^{3}$. Untuk konteks pengajaran di Indonesia sendiri, banyak kajian empiris yang fokus pada kecemasan para mahasiswa calon guru saat harus berhadapan dengan kelas nyata. Akan tetapi, penelitian-penelitian tersebut lebih terpusat pada kecemasan matematika ${ }^{4}$, kecemasan bahasa asing ${ }^{5}$, kecemasan di kelas teknologi informasi dan komunikasi (TIK) ${ }^{6}$, maupun kecemasan pada mahasiswa calon bidan pendidik ${ }^{7}$, sedangkan kajian relevan di kelas Pendidikan Agama Islam (PAI) masih sukar ditemukan ${ }^{8}$.

Kecemasan mengajar, jika ditinjau dari sudut pandang teori discrete emotions atau emosi diskrit $^{9}$, terkait erat dengan salah satu emosi negatif dasar yang dialami oleh individu. Perasaan cemas, menurut Frenzel, berhubungan dengan unsur afektif dan fisiologis seperti kondisi tubuh berkeringat atau gemetar sebagai akibat yang timbul dari perasaan ini. Selain itu, kecemasan juga berhubungan dengan unsur kognitif seperti timbulnya perasaan khawatir, keinginan untuk lari dari situasi baru yang akan atau sedang dihadapi, dan sebagainya ${ }^{10}$. Kecemasan mengajar, sebagai bagian dari emosi negatif pada calon guru, dapat dipengaruhi oleh ketidakpastian atau keadaan yang tidak bisa mereka prediksi seperti berada di tempat mengajar baru dengan suasana yang lain

${ }^{1}$ Christopher Day dan John Chi-Kin Lee, New Understandings of Teacher's Work: Emotions and Educational Change, (New York: Springer, 2011), h. 2.

2 Roisin Donnelly dan Marian Fitzmaurice, "Towards Productive Reflective Practice in Microteaching," Innovations in Education and Teaching International 48, no. 3 (2011), h. 335.

${ }^{3}$ Michael B. Ripski, Jennifer LoCasale-Crouch dan Lauren Decker, "Pre-Service Teachers: Dispositional Traits, Emotional States, and Quality of Teacher-Student Interactions”, Teacher Education Quarterly, Spring (2011), h. 77 .

${ }^{4}$ Ahmad Dzulfikar, "Kecemasan Matematika pada Mahasiswa Calon Guru Matematika," Jurnal Matematika dan Pendidikan Matematika I, no. 1 (2016), h. 34; Alberta Parinters Makur dan Rully Charitas Indra Prahmana, "Penyebab Kecemasan Matematika Mahasiswa Calon Guru Asal Papua," Jurnal Elemen 1, no. 10 (2015), h. 1; Ifada Novikasari, "Hubungan Antara Prestasi Belajar dan Tingkat Kecemasan Matematika pada Mahasiswa Calon Guru SD/MI," Aksioma 5, no. 2 (2016), h. 120.

5 Vina Agustina, "Pre-service Teachers' Anxiety during Teaching Practicum," English Review: Journal of English Education 2, no. 2 (2014), h. 174.

${ }^{6}$ Muhamad Arifin, Setiadi Cahyono Putro, dan Hadi Putranto, "Hubungan Kemampuan Efikasi Diri dan Kemampuan Kependidikan dengan Kesiapan menjadi Guru TIK Mahasiswa Pendidikan Teknik Informatika." Teknologi dan Kejuruan 37, no. 2 (2014), h. 129.

${ }^{7}$ Fidiya Rizka dan Dewi Rokhanawati, "Hubungan Kesiapan dengan Tingkat Kecemasan Menghadapi Real Teaching pada Mahasiswa DIV Bidan Pendidik Anvullen STIKES Aisyiyah Yogyakarta Tahun 2014." (Yogyakarta: STIKES ‘Aisyiyah Yogyakarta, 2014), h. 1.

${ }^{8}$ Lihat Ermis Suryana, "Analisis Kinerja Mahasiswa Peserta Micro Teaching FITK UIN Raden Fatah Palembang (Studi pada Mahasiswa Program Studi Pendidikan Agama Islam),” Tadrib IV, no. 1 (2018), h. 120.

${ }^{9}$ Carroll E. Izard, "Emotion Theory and Research: Highlights, Unanswered Questions, and Emerging Issues", Annual Review of Psychology 60, (2009), h. 1.

${ }^{10}$ A. C. Frenzel, "Teacher Emotions", dalam E. A. Linnenbrink-Garcia dan R. Pekrun (Ed.) International Handbook of Emotions in Education, (New York: Routledge, 2014), h. 498. 
dari biasanya. Ketidakpastian atau keadaan yang dianggap tidak bisa mereka prediksi seperti penerimaan pihak sekolah, baik pihak administrasi, guru maupun murid, terhadap keberadaan mereka di tempat baru tersebut yang menuntut mereka untuk melakukan penyesuaian atau adaptasi ${ }^{11}$.

Kajian empiris menemukan bahwa secara psikologis, calon guru maupun guru berada dalam kontinuum emosi positif dan emosi negatif ${ }^{12}$, dan kecemasan calon guru ada pada rentang emosi negatif. Hasil penelusuran literatur menunjukkan bahwa sumber kecemasan calon guru sangat beragam termasuk diantaranya pengalaman, tipe sekolah, kondisi fisik kelas dan sekolah, kepribadian, karakteristik siswa yang dihadapi, hubungan dengan pihak sekolah, konteks pengajaran, tingkat atau level pengajaran, masalah keluarga, dan/atau masalah keuangan ${ }^{13}$. Calon guru biasanya akan berusaha mengubah emosi negatif yang timbul menjadi emosi positif dengan melakukan upaya-upaya adaptasi terhadap lingkungan baru yang diharapkan bisa membantu mereka lebih mudah bersosialisasi dan mempelajari hal-hal yang perlu mereka kuasai selama menjalani tugas sebagai guru. Upaya adaptasi di tempat baru guna mengubah emosi negatif menjadi emosi positif adalah bagian dari proses sociolization-related learning yang dicetuskan Reio $^{14}$. Proses ini mencakup bagaimana guru atau mahasiswa calon guru secara proaktif mencari tahu informasi yang mereka butuhkan untuk menyelesaikan ketidakpastian yang akan mereka hadapi di suatu lingkungan baru dengan cara melakukan observasi dan konsultasi dengan guru pamong maupun dosen pembimbing guna memenuhi tuntutan menjadi seorang guru ${ }^{15}$.

Le Cornu menegaskan bahwa hal terpenting bagi mahasiswa calon guru atau guru baru adalah bagaimana mereka merefleksi upaya mengatasi emosi negatif menjadi emosi positif ${ }^{16}$ dengan mengubahnya menjadi optimisme belajar ${ }^{17}$, bagaimana mereka mengambil pelajaran dari pengalaman yang diperoleh di ruang-ruang kelas, dan bagaimana mereka menjadikan refleksi diri tersebut sebagai alat untuk menguasai kompetensi mengajar ${ }^{18}$ sehingga membentuk mereka menjadi guru yang tangguh. Refleksi sendiri sesungguhnya telah menjadi bagian integral guru yang berkualitas karena ia menjadi bagian penting dalam pengembangan pribadi maupun profesi guru sepanjang karirnya ${ }^{19}$. Dalam pemaparan hasil penelitian mengenai pengaruh pendekatan reflektif atas program pelatihan guru intensif, Lan dan Wang menyatakan bahwa pendekatan

${ }^{11}$ Reio Jr., Thomas G., "Teacher Emotions and Socialization-Related Learning in the Context of Educational Change", dalam Christopher Day dan John Chi-Kin Lee (Ed.), New Understandings of Teacher's Work: Emotions and Educational Change, (New York: Springer, 2011), h. 109.

${ }^{12}$ A. C. Frenzel, op. cit., h. 494.

${ }^{13}$ Vina Agustina, loc. cit.; Thomas G. Reio Jr. dan J. Callahan, "Affect, Curiosity, and Socialization-Related Learning: A Path Analysis of Antecedents to Job Performance," Journal of Business and Psychology 18, (2004), h. 35; Amy B. M. Tsui, Understanding Expertise in Teaching: Case Studies of Second Language Teachers, (New York: Cambridge University Press, 2003), h. 7.

${ }^{14}$ Thomas G. Reio Jr., op. cit. h. 107.

${ }^{15}$ Thomas G. Reio Jr. dan J. Callahan, op. cit. h. 38; Thomas G. Reio Jr., loc. cit.

${ }^{16}$ Rosie Le Cornu, "Building Early Career Teacher Resilience: The Role of Relationships," Australian Journal of Teacher Education 38, no. 4 (2013): h. 1.

${ }^{17}$ Thomas G. Reio Jr., op. cit. h. 109.

${ }^{18}$ Rosie Le Cornu, loc. cit.

${ }^{19}$ Sitti Nurfaidah, EFL Pre-service Teachers' Reflection: A Case Study in an Indonesian Instructional Context. (Disertasi Doktor Tidak Dipublikasi, Bandung: Universitas Pendidikan Indonesia, 2016), h. 240; Sitti Nurfaidah, Nenden Sri Lengkanawati dan Didi Sukyadi, "Levels of Reflection in EFL Pre-service Teachers' Teaching Journal," Indonesian Journal of Applied Linguistics 7, no. 1 (2017), h. 80. 
pengajaran reflektif berguna bagi guru dan calon guru untuk mempertajam keterampilan mengajar, memperkaya strategi mengajar dan keterampilan pengelolaan kelas, dan meningkatkan kesadaran akan pentingnya memperhatikan pengajaran secara reflektif dan pentingnya refleksi terhadap pengajaran mereka ${ }^{20}$.

Terkait studi terhadap kecemasan para calon guru, penelitian ini dianggap penting untuk dilakukan karena fenomena yang terlihat saat mereka berhadapan dengan tugas mengajar microteaching maupun dengan kelas nyata di lapangan menunjukkan adanya rasa cemas pada mereka ${ }^{21}$. Kajian terhadap kecemasan atau anxiety yang dihadapi oleh mahasiswa calon guru saat mereka praktek mengajar di sekolah lebih banyak mengeksplorasi hasil data kuantitatif, sedangkan penelitian yang menggunakan pendekatan eksploratori masih terbatas dalam konteks Indonesia. Sumber data bagi penelitian eksploratori seringkali diperoleh dari hasil refleksi mengajar, baik dalam bentuk diskusi informal maupun yang tertuang dalam jurnal refleksi mengajar atas keberadaan dan keterlibatan mereka selama di sekolah ${ }^{22}$.

Penelitian pendahuluan ini menggunakan desain studi kasus yang hendak memahami dan mendapatkan gambaran pengalaman nyata mahasiswa calon guru terkait kecemasan yang mereka hadapi saat terjun langsung mengajar di kelas nyata. Studi kasus ini bersifat pendahuluan karena dari hasil analisis data diharapkan dapat membantu peneliti lebih memahami fenomena kecemasan mahasiswa calon guru dan menjadi hipotesis bagi penelitian relevan selanjutnya ${ }^{23}$. Partisipan yang terlibat adalah mahasiswa calon guru Pendidikan Agama Islam yang melaksanakan program PPL selama kurang lebih dua bulan. Sepuluh mahasiswa, yang terdiri atas tiga laki-laki dan tujuh perempuan, ditugaskan mengajar di salah satu sekolah menengah atas di Kota Kendari. Sekolah tersebut memiliki reputasi yang baik di tingkat provinsi sehingga mahasiswa calon guru yang ditugaskan mengajar di sekolah tersebut adalah mereka yang benar-benar memiliki kemampuan mengajar yang baik ${ }^{24}$.

Data dikumpul melalui jurnal refleksi serta wawancara atas hal-hal yang membutuhkan klarifikasi atau penjelasan lanjut yang tidak ditemukan di jurnal refleksi mereka. Para partisipan diminta untuk menulis refleksi hari pertama di sekolah, lalu refleksi observasi, diikuti dengan refleksi akhir pekan. Semua refleksi dikirim ke email peneliti untuk diolah lebih lanjut. Dari hasil analisis jurnal refleksi dan wawancara, untuk beberapa data diputuskan untuk diikuti dengan wawancara mendalam karena peneliti membutuhkan klarifikasi atas beberapa hal yang belum jelas di jurnal partisipan. Display dalam artikel ini, baik data dari jurnal refleksi maupun hasil wawancara telah melalui proses simplifikasi untuk memudahkan keterbacaan data tanpa

${ }^{20}$ Mei Hua Lan dan Kai-Ping Wang, "The Effects of Reflective Teaching on an Intensive Teacher Training Program", Indonesian Journal of Applied Linguistics 3, no.1 (2013), h. 82, 97.

${ }^{21}$ Amy B. M. Tsui, op. cit., h. 8.

${ }^{22}$ Hedi Budiman, "Pengajaran Reflektif Mahasiswa Calon Guru Pendidikan Matematika," Jurnal PRISMA VI, no. 21 (2017), h. 132.

${ }^{23}$ Bent Flyvbjerg, "Five Misunderstandings about Case-Study Research," Qualitative Inquiry 12, no. 2, (2006), h. 219.

${ }^{24}$ FGD Evaluasi dan Refleksi Program PPL II Fakultas Tarbiyah dan Ilmu Keguruan IAIN Kendari Tahun 2018, 2 November 2018. 
mengubah substansi isi dan makna data tersebut ${ }^{25}$. Disamping itu, untuk melindungi identitas partisipan, identitas mereka menggunakan nama samaran ${ }^{26}$.

\section{B. Refleksi Kecemasan Calon Guru Dalam Program Praktek Pengalaman Lapangan}

Refleksi, seperti yang diyakini oleh banyak pihak, adalah cara yang dapat membantu mempercepat proses pengembangan kemampuan mengajar mahasiswa calon guru ${ }^{27}$. Dengan melakukan refleksi setelah mengajar, mahasiswa calon guru dapat mengevaluasi pengajaran yang telah dilakukan di kelas ${ }^{28}$ sehingga dapat melakukan perbaikan dan persiapan yang lebih matang untuk pengajaran berikutnya ${ }^{29}$. Dalam penelitian ini, eksplorasi kecemasan calon guru tertuang dalam jurnal refleksi yang difokuskan pada kecemasan mereka menghadapi hari pertama masuk ke sekolah tempat mengajar dan kecemasan saat pertama kali mengajar di kelas. Pemaparan temuan dan pembahasan hasil penelitian ini terpusat pada tema kecemasan tersebut di atas.

\section{B.1 "Saya Takut Tidak Bisa Jadi Guru yang Baik": Kecemasan Mahasiswa Calon Guru di Hari Pertama}

Hasil refleksi dan wawancara mendalam mahasiswa calon guru terkait pengalaman mereka saat pertama kali berada di sekolah tempat PPL menunjukkan kecemasan terhadap beberapa hal, yaitu cemas akan keberhasilan mereka di sekolah tersebut, cemas akan penerimaan pihak sekolah-kepala sekolah, guru, siswa, maupun tenaga administratif-yang belum pasti, serta cemas dengan performa mengajar di kelas dan kaitannya dengan kesuksesan belajar serta prestasi siswa.

Dari hasil analisis jurnal dan wawancara, refleksi partisipan menunjukkan bahwa mereka semua merasa cemas di hari pertama turun ke lapangan. Kecemasan mereka pada dasarnya berhubungan dengan rasa tidak percaya diri akan kemampuan mengajar dan di saat yang sama mereka sadar akan kapasitas ilmu yang belum memadai padahal mereka harus mengajar di sekolah yang bereputasi. Prestasi sekolah maupun siswa telah memicu kecemasan sehingga mereka khawatir tidak mampu melakukan yang terbaik bagi sekolah maupun siswa yang mereka hadapi. Data jurnal maupun wawancara menunjukkan bahwa sebelum praktikum di sekolah dimulai, mereka sudah membangun persepsi bahwa mahasiswa calon guru yang mengajar di sekolah tersebut seyogyanya mereka dengan kemampuan mengajar yang mumpuni, sedangkan mereka merasa belum sampai pada kompetensi itu. Berikut beberapa petikan data jurnal refleksi mahasiswa calon guru Pendidikan Agama Islam terkait pengalaman mereka sebelum turun ke lapangan dan di hari pertama masuk ke sekolah tersebut.

${ }^{25}$ C. F. Auerbach dan L. B. Silverstein, Qualitative Data: An Introduction to Coding and Analysis, (New York: New York University Press, 2003), h. 78.

${ }^{26}$ Ranbir Singh Malik dan Fuad Abdul-Hamied, Research Methods: A Guide for First Time Researchers, (Bandung: UPI Press, 2014), h. 83.

${ }^{27}$ Colin J. Marsh, Becoming a Teacher: Knowledge, Skills and Issues, (Frenchs Forest, NSW: Pearson Education Australia, 2008), h. 7.

${ }^{28}$ Stephen D. Brookfield, Becoming a Critically Reflective Teacher, (San Francisco, California: Jossey-Bass, Inc., Publishers, 1995), h. 3.

${ }^{29}$ Donald A. Schön, Educating the Reflective Practitioner, (New York: Basic Books, 1987), h. 5. 


\begin{abstract}
Sebelum turun ke sekolah saya diliputi ketakutan. Sejak saya mengetahui lokasi PPL II saya di sekolah ini, saya histeris menangis karena info dari teman-teman sekolah ini adalah salah satu sekolah favorit di Sulawesi Tenggara. Selain itu, sekolah tersebut sangat diminati berbagai kalangan masyarakat yang ingin anaknya terdaftar di sekolah ini meskipun harus melewati tahapan seleksi yang sangat ketat. Siswa-siswanya pun banyak yang berprestasi, dari tingkat kabupaten hingga tingkat nasional. Hal ini membuat saya ragu dan dipenuhi rasa takut karena ketidakpercayaan diri saya yang membuat rasa takut seakan menghantui saya. Semalaman saya berfikir rasanya ingin menghubungi pihak pengelola PPL agar saya dipindahkan di sekolah lain, namun ternyata tidak bisa lagi pindah lokasi PPL II. Akhirnya, saya menelpon bapak saya untuk meminta motivasi agar ketakutan saya hilang. Ini karena bapak saya adalah motivator terhebat saya yang selalu memberikan saya wejangan/motivasi dari mulai duduk di bangku SMP kelas 1 sampai sekarang." 30
\end{abstract}

Refleksi Endang, mahasiswa calon guru di atas menunjukkan bagaimana rasa takut melingkupinya saat mengetahui di sekolah mana ia ditugaskan mengajar. Emosi negatif seperti keraguan, ketakutan, dan ketidakpercayaan diri menyerang karena ia khawatir tidak bisa mencapai standar guru yang baik di sekolah bereputasi tersebut. Akan tetapi, ia mencoba mencari jalan keluar dengan melakukan konsultasi dengan ayahnya yang ia percaya selama ini selalu berhasil membangun kepercayaan dirinya.

Hal yang sama juga terjadi pada Sari, partisipan yang mengungkapkan bagaimana emosi negatif menguasainya sebelum mereka diterjunkan ke lapangan. Dalam petikan refleksi di bawah ini, Sari mempertanyakan kemampuan dirinya sendiri. Berikut catatan jurnal yang merefleksikan keraguan tersebut.

Sebelum masuk di sekolah ini berbagai macam pikiran negatif sudah ada di kepala saya dan membuat saya takut. Saya bertanya sendiri kepada diri sendiri: Apakah saya bisa mengajar? Bagaimana dengan ilmu yang saya dapatkan di perkuliahan, apakah sudah maksimal? Yah, seperti itulah pikiran saya. Untung teman-teman selalu memberi semangat kepada saya. Semuanya berjalan lancar. Kami diterima dengan baik dan saya sangat senang. ${ }^{31}$

Refleksi pengalaman Sari sebelum masuk ke tempat mengajar yang baru menegaskan apa yang dipaparkan oleh Tsui bahwa guru - calon guru, guru baru, maupun guru berpengalaman - selalu dihadapkan dengan tantangan ${ }^{32}$. Hanya saja tantangan yang mereka hadapi berbeda-beda. Tantangan yang seringkali menghadang calon guru atau guru baru adalah hal-hal dasar terkait kemampuan menghadapi kelas, seperti bagaimana menyajikan materi dengan baik, menjaga ketertiban kelas dan menerapkan disiplin ${ }^{33}$. Ketika mereka berhasil menghadapi tantangan tersebut, maka mereka sudah berupaya meningkatkan tingkat kompetensi mereka ke level yang lebih tinggi ${ }^{34}$. Hal ini tergambar dari petikan refleksi berikut.

Saya mempersiapkan banyak hal sebelum turun ke sekolah mulai dari mempersiapkan diri, pengetahuan, dan mental agar saya benar-benar maksimal dalam pelaksanaan PPL nanti. Ketika saya memasuki lingkungan sekolah untuk pertama kalinya, saya merasa gugup, khawatir dan takut karena saya tahu prestasi sekolah ini. Siapa yang tidak tahu prestasi siswa di sekolah ini? Hal inilah yang menyebabkan saya merasa gugup sejak awal karena prestasi sekolah maupun siswanya. Akan tetapi, ketika prosesi penyerahan dari pihak kampus

${ }^{30}$ Endang, Jurnal Refleksi Hari Pertama PPL

${ }^{31}$ Sari, Jurnal Refleksi Hari Pertama PPL

${ }^{32}$ Amy B. M. Tsui, op. cit. h. 8

${ }^{33}$ Ibid

${ }^{34}$ Amy B. M. Tsui, op. cit. h. 244 
ke pihak sekolah selesai, perasaaan saya bercampur aduk mulai dari lega dan perasaan mulai dibebani oleh amanah untuk mengajar. Penyambutan dan respon yang cukup baik dari pihak sekolah kepada kami membuat kami merasa senang dan terharu karena mendapat apresiasi yang cukup baik. ${ }^{35}$

Pada awal menghadapi program PPL II ini saya deg-degan karena sekolah ini masih terasa asing buat saya. Tetapi setelah menjalaninya hari demi hari, akhirnya terasa biasa dan perlahan-lahan deg-degan itu hilang. ${ }^{36}$

Refleksi Hani maupun Lukman di atas memberikan gambaran bagaimana ketidakpastian kondisi yang akan mereka hadapi di tempat mengajar mampu memengaruhi emosi mereka secara negatif sehingga timbul rasa gugup, khawatir, dan takut menghadapi situasi baru. Sebelum memasuki sekolah tempat mereka ditugaskan, Hani maupun Lukman diliputi ketidakpastian apa yang akan mereka hadapi nantinya di sekolah. Ketidakpastian tersebut terkait dengan bagaimana penerimaan pihak sekolah terhadap mereka, materi apa yang akan diajarkan, metode pengajaran apa yang akan digunakan, bagaimana menghadapi siswa di kelas, dan sebagainya. Dengan berlalunya waktu dan dimulainya masa observasi sekolah, konsultasi dengan guru pamong, dan sosialisasi dengan lingkungan sekolah yang baru, maka proses adaptasi dan sosialisasi mulai terinternalisasi dalam diri mahasiswa calon guru ${ }^{37}$ sehingga rasa cemas mereka perlahan-lahan berkurang.

Data di atas mewakili pengakuan semua partisipan atas kecemasan mereka di awal program PPL di sekolah. Kecemasan tampak beberapa saat sebelum mereka terjun langsung ke sekolah. Seluruh hasil refleksi partisipan dalam penelitian ini mengonfirmasi argumen Day dan Lee bahwa kecemasan mengajar, yang masuk dalam ranah emosi guru ${ }^{38}$, bisa timbul karena kondisi ketidakpastian yang dialami oleh guru atau calon guru ${ }^{39}$. Ketidakpastian ini terkait erat dengan tuntutan perubahan diri untuk menjadi guru yang sukses mengajar di tempat baru. Kecemasan yang timbul di diri partisipan pada penelitian ini mendukung hasil penelitian Tsui yang mendapati bahwa baik mahasiswa calon guru maupun guru baru menunjukkan kecemasan terkait kompetensi penguasaan materi, metode pengajaran, kemampuan manajemen kelas, dan pencapaian siswa ${ }^{40}$.

Untuk mengatasi kecemasan ini, partisipan mengaku mempersiapkan diri secara fisik dan mental, serta memperkuat kembali pengetahuan yang sudah didapatkan di bangku kuliah. Dengan kata lain, mereka membekali diri dengan kompetensi pedagogik dan kompetensi profesional guru jauh hari sebelumnya. Sebelum turun ke lapangan, mereka sudah mempertimbangkan berbagai hal, termasuk aspek penguasaan psikologi pembelajaran yang meliputi bagaimana memahami siswa sebagai pelajar, memilih metode pembelajaran yang tepat untuk peserta didik, manajemen kelas, dan sebagainya. Akan tetapi, pada kenyataannya, saat mereka turun ke lapangan dan berhadapan dengan kelas yang nyata, kecemasan tetap melanda diri mereka.

Kendatipun kecemasan menyerang, dengan persiapan yang dianggap cukup sebelum turun ke lapangan, mereka berusaha mengubah emosi negatif tersebut menjadi emosi positif dengan melakukan upaya-upaya adaptasi terhadap lingkungan baru. Upaya adaptas ${ }^{41}$ dilakukan dengan

\footnotetext{
${ }^{35}$ Hani, Jurnal Refleksi Hari Pertama PPL

${ }^{36}$ Lukman, Jurnal Refleksi Hari Pertama PPL

${ }^{37}$ Thomas G. Reio Jr., op. cit., h. 105.

${ }^{38}$ Christopher Day dan John Chi-Kin Lee, op. cit., h. 2.

${ }^{39}$ Thomas G. Reio Jr., op. cit., h. 109.

${ }^{40}$ Amy B. M. Tsui, op. cit., h. 8

${ }^{41}$ Carroll E. Izard, op. cit., h. 1.
} 
mengamati lingkungan baru serta berbaur dengan situasi dan kondisi di lingkungan baru tersebut. Upaya adaptasi ini diharapkan bisa membantu mereka lebih mudah bersosialisasi dan mempelajari hal-hal yang perlu mereka kuasai selama menjalani tugas sebagai guru. Hal ini sejalan dengan terma sociolization-related learning karena mahasiswa calon guru menunjukkan upaya proaktif mencari tahu informasi yang dibutuhkan agar bisa menghadapi situasi dan kondisi di sekolah tersebut ${ }^{42}$ melalui upaya observasi yang intensif serta konsultasi dengan guru pamong maupun dosen pembimbing untuk mencapai tujuan program PPL, menjadi guru yang baik dan sukses membagi ilmu ke anak didik ${ }^{43}$.

\section{B.2 "Mereka Sangat Bersemangat, Mengapa Saya Tidak?": Kecemasan Mengajar Pertama Kali}

Terkait refleksi pengalaman mengajar untuk pertama kalinya, data jurnal refleksi mahasiswa calon guru menunjukkan hal yang variatif. Ada yang mengungkapkan bahwa meskipun sudah berada dalam lingkungan sekolah dan bersosialisasi selama seminggu lebih, akan tetapi pada saat mereka mendapat tugas mengajar untuk pertama kali di kelas, mereka tetap diliputi kecemasan. Mereka takut akan beberapa hal, seperti takut tidak bisa menangani kelas dengan baik, khawatir tidak mampu menyampaikan materi agar siswa paham, cemas jangan-jangan siswa tidak mau diajar hanya karena posisi mereka sebagai guru PPL. Akan tetapi, ada pula partisipan yang merasa kecemasannya berangsur-angsur hilang dan mulai percaya diri saat mengajar pertama kali disebabkan dukungan lingkungan sekolah yang kondusif terhadap keberadaan mereka. Mereka tidak lagi merasa cemas ketika mendapati bahwa sosialisasi mereka di tempat baru ternyata tidak serumit yang mereka bayangkan sebelumnya. Di sekolah tersebut mereka berinteraksi dengan siswa yang ramah dan santun, guru pamong yang sangat perhatian dan selalu memberikan bimbingan terkait persiapan pengajaran dan cara menangani kelas, serta staf administrasi dan pimpinan sekolah yang sangat menerima keberadaan mereka di sekolah. Hal ini tergambar dalam refleksi berikut.

Dalam minggu ini saya mengajar untuk pertama kalinya. Alhamdullilah, berbeda dengan ketika belum melaksanakan pembelajaran di dalam kelas saat saya masih merasa khawatir dan grogi, sekarang saya sudah merasa santai, rileks dalam menjelaskan materi pembelajaran. Pengalaman yang tak terlupakan saat pembelajaran pertama di dalam kelas di mana rasa grogi saya hilang seketika saat siswa sangat antusias dan asyik selama dalam proses pembelajaran. Hal itu membuat diri saya merasa bersemangat, sangat senang dan senantiasa berupaya untuk memperbaiki hal-hal yang masih kurang terkait pengelolaan di dalam kelas.

Saat pertemuan pertama ini saya menggunakan media gambar mengenai peristiwa rasul di zamannya, karena materi saya tentang "Iman kepada Rasul-Rasul Allah SWT" dan dalam menjelaskan arti beriman kepada rasul Allah SWT saya tugaskan mereka membuat sebuah kalimat berbentuk puisi atau apapun itu untuk mengekspresikan rasa cinta dan keyakinan mereka terhadap Rasul. Hal ini sangat memancing antusiasme mereka dalam proses pembelajaran di dalam kelas dan melihat keterampilan yang mereka miliki.

Dalam memulai pembelajaran pertama ini, saya juga menggunakan warm-up atau ice breaking, dengan mengarahkan mereka untuk membuat jargon-jargon sebuah kalimat yang bagus ketika ada guru yang menanyakan kabar mereka. Dan sebelum memulai pembelajaran saya juga mengarahkan mereka untuk tadarrus bersama sebelum belajar yang bacaan ayatnya sesuai dengan materi yang akan diajarkan, dan juga memberikan sebuah motivasi kalimat dan mereka menjelaskannya yang kalimat yang mebuat mereka

${ }^{42}$ Thomas G. Reio Jr., op. cit. h. 107.

${ }^{43}$ Thomas G. Reio Jr. dan J. Callahan, op. cit. h. 35; Thomas G. Reio Jr., op. cit. h. 107. 
antusias dalam memulai proses pembelajaran. Mereka berlomba-lomba angkat tangan untuk mengartikan kalimat tersebut.

Akan tetapi, saya merasa masih mempunyai kekurangan dalam pertemuan pertama, karena masih ada satu dua siswa di akhir pembelajaran masih belum terlihat antusias dalam diskusi kelompok dan dalam pembelajaran di dalam kelas, mungkin dikarenakan sudah dekat dengan waktu pulang mereka. Ini membuat saya untuk termotivasi untuk lebih bersemangat agar siswa secara keseluruhan terlibat aktif dalam proses diskusi hingga akhir pertemuan. Harapan saya ilmu yang mereka dapatkan bukan sekedar disimpan di dalam pikiran tetapi juga diaplikasikan dalam kehidupan mereka sehari-hari.

Untuk mencapai tujuan itu, sampai saat ini saya harus senantiasa menanamkan motivasi dalam diri saya untuk selalu bersemangat dalam melaksanakan aktivitas di sekolah baik dalam hal mengajar dan menyelesaikan tugas-tugas perangkat pembelajaran agar kegiatan selama PPL ini bukan saja sekedar menyelesaikan program ini tapi juga mendapatkan ilmu, pengalaman, keberkahan, serta ridho dari Allah SWT untuk perubahan yang lebih baik dan perjalanan hidup saya di masa depan nantinya. ${ }^{44}$

Refleksi mengajar Aisyah tersebut di atas menunjukkan bagaimana perasaan khawatir dan grogi menghadapi kelas untuk pertama kalinya perlahan-lahan hilang karena penerimaan siswa terhadap dirinya dan materi yang dibawakan sangat positif. Melihat persiapan Aisyah yang cukup matang sebelum masuk ke kelas, seperti menyiapkan kegiatan pembuka pelajaran yang mampu memancing antusiasme siswa serta upaya membuat siswa aktif dalam kegiatan di kelas, tidak mengherankan jika rasa gugup menghadapi kelas baru jadi berkurang dan hilang sejalan waktu aktivitas mengajar yang dilaluinya. Hal serupa juga diungkapkan oleh Rina dan dalam catatan refleksi berikut ini.

Pengalaman saya pada saya mengajar pertama kali di kelas awalnya diliputi perasaan gugup dan cemas. Tetapi saya anggap itu hal biasa, apalagi ini hari pertama mengajar karena setelah berlangsungnya pembelajaran rasa gugupku pun hilang. Siswa-siswanya sangat antusias mengikuti pelajaran. Melihat hal ini, saya sebagai seorang guru berpikir kalau siswanya seperti ini, maka saya sebagai seorang guru tidak boleh kalah semangat. Sebelum saya masuk mengajar di kelas ini saya sudah memikirkan media apa yang akan digunakan. Saya sangat senang karna siswapun sangat antusias dan senang dalam proses pembelajaran yang berlangsung. Masukan dari guru pamong yang diberikan kepada saya yaitu cara mengatur waktu dalam proses pembelajaran. Setelah aktivitas mengajar ini, saya merasa masih ada yang kurang ataupun perlu diperbaiki terutama dalam manajemen waktu. Minggu berikutnya saya akan berusaha memperbaikinya. ${ }^{45}$

Ketika mengajar pertama kali di kelas, saya merasa agak kurang percaya diri. Tapi berbekal semangat dan penguasaan materi, semua terasa berlalu dengan cepat dan terasa santai. Ini mungkin karena kami sudah terbiasa melakukan pembelajaran yang sama seperti pada microteaching, ditambah dengan kami telah mengamati bagaimana guru pamong kami membawakan materi saat observasi. Tetapi saya masih merasa ada yang kurang walapun sudah menyelesaikannya dengan tuntas, karena saya juga masih dalam tahap belajar mengajar. ${ }^{46}$

Data refleksi mengajar di atas memberikan gambaran tentang upaya-upaya yang dilakukan oleh mahasiswa calon guru baik dalam tahap persiapan mengajar, saat mengajar, maupun evaluasi setelah mengajar. Upaya-upaya seperti mempersiapkan perangkat pembelajaran dengan sebaikbaiknya, memancing antusiasme siswa dalam kelas, menciptakan suasana belajar yang kondusif, menyiapkan media belajar yang menarik, dan menggunakan teknik warm-up saat membuka

\footnotetext{
${ }^{44}$ Aisyah, Jurnal Refleksi Mengajar Pertama Kali

${ }^{45}$ Rina, Jurnal Refleksi Mengajar Pertama Kali

${ }^{46}$ Hani, Jurnal Refleksi Mengajar Pertama Kali
} 
pelajaran dan ice-breaking yang tepat saat melihat kejenuhan di tengah-tengah proses belajar, telah membantu mereka keluar dari pusaran emosi negatif yang mereka rasakan.

Antusiasme siswa dan penerimaan siswa terhadap keberadaan calon guru di dalam kelas telah membantu mengatasi rasa gugup dan cemas yang timbul saat partisipan menghadapi kelas untuk pertama kalinya serta menjadi dorongan bagi mereka untuk melakukan yang terbaik dalam aktivitas pengajarannya. Dorongan ini, setelah melalui proses refleksi atas proses mengajar yang mereka lalui, telah menimbulkan kesadaran di diri mereka untuk mengevaluasi kekurangan yang masih ditemui dalam kegiatan di kelas demi perbaikan kualitas pengajaran selanjutnya. Temuan penelitian ini mengonfirmasi pernyataan Le Cornu yang menegaskan bahwa hal yang terpenting bagi mahasiswa calon guru adalah bagaimana proses refleksi bisa membantu mereka mengubah emosi negatif menjadi emosi positif melalui sikap optimisme belajar terhadap apa yang mereka hadapi di ruang-ruang kelas, dan bagaimana menjadikan proses refleksi tersebut membantu mereka menguasai kompetensi mengajar sehingga terbentuk guru yang reflektif dan berkualitas ${ }^{47}$.

Berbeda dengan argumentasi yang diajukan oleh Stahl, Sharplin, dan Kehrwald bahwa sebagian guru melakukan penolakan terhadap perubahan karena mereka kurang termotivasi, pemahaman dan pengalamannya kurang, dan mereka tidak berani mengambil resiko karena takut kepercayaan diri mereka terluka ${ }^{48}$, partisipan penelitian ini menunjukkan keterbukaan atas hal-hal yang baru untuk mereka pelajari. Sejalan dengan waktu, mereka semakin termotivasi untuk melakukan yang terbaik dalam proses belajar mengajar di kelas. Oleh karena itu, pihak pendidik calon guru perlu memerhatikan aspek socialization-related learning karena berguna untuk memfasilitasi pembelajaran dan adaptasi berkelanjutan untuk semua guru yang menghadapi tuntutan perubahan yang semakin dinamis di dunia pendidikan ${ }^{49}$.

\section{Implikasi Pendekatan Reflektif daalam Program LPTK}

Salah satu tantangan utama yang dihadapi oleh program Lembaga Pendidikan Tenaga Keguruan (LPTK) serta para pendidik calon guru yang terlibat di dalamnya adalah "how to assist pre-service teachers to become confident, reflective practitioners, and learners of their own teaching practice" ${ }^{\text {" }}$. Dengan kata lain, dosen di LPTK dituntut untuk mampu membentuk calon guru yang percaya diri, bisa menjadi guru reflektif, dan mampu belajar dari pengalaman mengajar di ruang kelasnya sendiri sehingga mereka tidak menjadi guru pemula yang merasa terasingkan dan mengalami trauma transisi dari calon guru ke guru di kelas nyata pada tahun-tahun awal mengajar. ${ }^{51}$ Sejalan dengan hal ini, Mustaqim mengindikasikan perlunya "restorasi kegiatan PPL sehingga kompetensi lulusan kegiatan PPL dapat lebih terstandar dari sebelumnya dan tujuan PPL dapat dicapai dengan optimal". ${ }^{52}$ Lebih lanjut Mustaqim menegaskan restorasi perlu difokuskan pada beberapa hal termasuk inovasi manajemen kurikulum PPL menggunakan pendekatan craft,

\footnotetext{
${ }^{47}$ Rosie Le Cornu, op. cit., h. 1.

${ }^{48}$ Garth Stahl, Erica Sharplin, dan Ben Kehrwald, "Developing Pre-service Teachers' Confidence: Real-time Coaching in Teacher Education", Reflective Practice, (2016), h. 1

${ }^{49}$ Thomas G. Reio Jr. dan J. Callahan, op. cit., h. 35.

${ }^{50}$ Bruce Johnson, Barry Down, Rosie Le Cornu, Judy Peters, Anna Sullivan, Jane Pearce, dan Janet Hunter, "Promoting Early Career Teacher Resilience: A Framework for Understanding and Acting," Teachers and Teaching 20, no. 5 (2014), h. 530.

${ }^{51}$ ibid

${ }^{52}$ Mujahidil Mustaqim, "Restorasi Praktek Pengalaman Lapangan (Studi Inovasi Manajemen Kurikulum PPL melalui Kolaborasi Pendekatan Craft, Competency, dan Reflective Model," EduTech 16, no. 2 (2017), h. 170, 187.
} 
competency, dan reflective model melalui perumusan kriteria keberhasilan PPL dan rencana pembelajaran PPL yang digunakan sebagai pedoman bagi guru pamong dalam mendidik praktikan ${ }^{53}$.

Di samping itu, terkait maksimalisasi kualitas guru PAI di sekolah, LPTK perlu menyiapkan calon guru PAI yang utuh yang mampu menguasai bidang studi secara terintegrasi dengan pemahaman mengenai peserta didik yang akan dihadapi, persiapan pembelajaran, pelaksanaan proses belajar mengajar yang mendidik, dan pelaksanaan evaluasi pembelajaran tanpa mengabaikan sifat dunia yang dinamis yang serta merta menuntut guru yang dinamis ${ }^{54}$. Bangun kesadaran atau awareness akan pentingnya memahami perubahan dalam dunia pendidikan, khususnya kesadaran akan kompetensi pedagogik, kompetensi kepribadian, kompetensi sosial, dan kompetensi profesional secara utuh dapat dimulai sejak dini di LTPK melalui penerapan dan pembiasaan pendekatan reflektif ${ }^{55}$. Tujuan jangka panjang melibatkan mahasiswa calon guru dalam kegiatan refleksi adalah membentuk sikap guru reflektif di diri mereka sejak dini. Dengan kata lain, sejak awal masuk dalam lingkungan kampus, mahasiswa dididik untuk menjadi caloncalon guru yang memiliki sifat terbuka (openminded), bertanggungjawab (responsible), dan sungguh-sungguh dalam bertindak (wholehearted $)^{56}$ atas segala dinamika yang terjadi di lingkungan tempat mereka belajar maupun mengajar nantinya.

\section{Penutup}

Hasil penelitian pendahuluan ini menunjukkan bahwa mahasiswa calon guru mengalami kecemasan di hari pertama mereka berada di lokasi PPL. Akan tetapi hal tersebut berkurang sejalan dengan keterlibatan mereka dengan tugas observasi dan administrasi sekolah. Kecemasan lain yang mereka alami adalah saat mereka dihadapkan dengan tugas mengajar untuk pertama kali di hadapan siswa. Dari hasil refleksi terungkap beragam alasan terkait kecemasan saat mengajar di depan kelas nyata untuk pertama kalinya, seperti cemas tidak mampu menyampaikan materi dengan baik dan cemas tidak bisa menjadi guru yang baik. Studi pendahuluan ini mengimplikasikan perlunya kajian yang lebih mendalam dan komprehensif terkait faktor psikologis yang dihadapi mahasiswa calon guru saat mereka melaksanakan program PPL dan bagaimana langkah yang harus ditempuh oleh pihak LPTK. Studi ini juga mengindikasikan perlunya penerapan dan pembiasaan pendekatan reflektif di LPTK untuk membentuk calon guru yang reflektif serta berkualitas yang mampu menghadapi tuntutan perubahan yang kerap terjadi di dunia pendidikan.

\section{Daftar Pustaka}

Agustina, Vina. "Pre-service Teachers' Anxiety during Teaching Practicum.” English Review: Journal of English Education, Vol. 2, No. 2 (2014): 174-182.

\footnotetext{
${ }^{53}$ Mujahidil Mustaqim, op. cit., h. 187.

${ }^{54}$ Muhammad Nasir, op. cit., h. 193.

${ }^{55}$ Sitti Nurfaidah, dkk., op. cit., h. 89

${ }^{56}$ Hedi Budiman, op. cit., h. 142; Sitti Nurfaidah, "Three Attitudes of a Reflective Teacher," Research and Innovation in Language Learning 1, no. 1 (2018), h. 39.
} 
Al Izzah: Jurnal Hasil-Hasil Penelitian-ISSN: 1978-9726 (p); 2541-0717 (e)

Volume 13, Nomor 2 (November, 2018)

Arifin, Muhamad, Setiadi Cahyono Putro, dan Hadi Putranto. "Hubungan Kemampuan Efikasi Diri dan Kemampuan Kependidikan dengan Kesiapan menjadi Guru TIK Mahasiswa Pendidikan Teknik Informatika.” Teknologi dan Kejuruan 37, No. 2 (2014): 129-136.

Auerbach, C. F., dan L. B. Silverstein. Qualitative Data: An Introduction to Coding and Analysis. New York: New York University Press, 2003.

Brookfield, Stephen D. Becoming a Critically Reflective Teacher. San Francisco, California: Jossey-Bass, Inc., Publishers, 1995.

Budiman, Hedi. "Pengajaran Reflektif Mahasiswa Calon Guru Pendidikan Matematika." Jurnal PRISMA VI, No. 21 (2017): 132-143.

Day, Christopher, dan John Chi-Kin Lee. New Understandings of Teacher's Work: Emotions and Educational Change. New York: Springer, 2011.

Donnelly, Roisin, dan Marian Fitzmaurice. "Towards Productive Reflective Practice in Microteaching". Innovations in Education and Teaching International 48, No. 3 (2011): 335346. doi: 10.1080/14703297.2011.593709

Dzulfikar, Ahmad. "Kecemasan Matematika pada Mahasiswa Calon Guru Matematika." Jurnal Matematika dan Pendidikan Matematika I, No. 1 (2016): 34-44.

Flyvbjerg, Bent. "Five Misunderstandings about Case-Study Research," Qualitative Inquiry 12, No. 2 (2006): 219-245. doi: 10.1177/1077800405284363.

Frenzel, A. C. "Teacher Emotions", dalam E. A. Linnenbrink-Garcia dan R. Pekrun (Ed.) International Handbook of Emotions in Education. New York: Routledge, 2014.

Izard, Carroll E. "Emotion Theory and Research: Highlights, Unanswered Questions, and Emerging Issues". Annual Review of Psychology 60, (2009): 1-25.

Johnson, Bruce, Barry Down, Rosie Le Cornu, Judy Peters, Anna Sullivan, Jane Pearce, dan Janet Hunter. "Promoting Early Career Teacher Resilience: A Framework for Understanding and Acting." Teachers and Teaching 20, No. 5 (2014): 530-546, doi: $10.1080 / 13540602.2014 .937957$

Lan, Mei Hua, dan Kai-Ping Wang. "The Effects of Reflective Teaching on an Intensive Teacher Training Program". Indonesian Journal of Applied Linguistics 3, No.1 (2013): 81-102.

Le Cornu, Rosie. "Building Early Career Teacher Resilience: The Role of Relationships." Australian Journal of Teacher Education 38, No. 4 (2013): 1-16.

Makur, Alberta Parinters, dan Rully Charitas Indra Prahmana. "Penyebab Kecemasan Matematika Mahasiswa Calon Guru Asal Papua.” Jurnal Elemen 1, No. 10 (2015): 1-12. 
Al Izzah: Jurnal Hasil-Hasil Penelitian-ISSN: 1978-9726 (p); 2541-0717 (e)

Volume 13, Nomor 2 (November, 2018)

Malik, Ranbir Singh, dan Fuad Abdul-Hamied. Research Methods: A Guide for First Time Researchers. Bandung: UPI Press, 2014.

Marsh, Colin J. Becoming a Teacher: Knowledge, Skills and Issues. Frenchs Forest, NSW: Pearson Education Australia, 2008.

Mustaqim, Mujahidil. "Restorasi Praktek Pengalaman Lapangan (Studi Inovasi Manajemen Kurikulum PPL melalui Kolaborasi Pendekatan Craft, Competency, dan Reflective Model)." EduTech 16, No. 2 (2017): 170-188.

Nasir, Muhammad. "Profesionalisme Guru Agama Islam (Sebuah Upaya Peningkatan Mutu Melalui LPTK)". Dinamika Ilmu 13, No. 2 (2013): 189-203.

Novikasari, Ifada. "Hubungan Antara Prestasi Belajar dan Tingkat Kecemasan Matematika pada Mahasiswa Calon Guru SD/MI." Aksioma 5, No. 2 (2016): 120-127. doi: 10.24127/ajpm.v5i2.671

Nurfaidah, Sitti. EFL Pre-service Teachers' Reflection: A Case Study in an Indonesian Instructional Context. Disertasi Doktor Tidak Dipublikasi, Bandung: Universitas Pendidikan Indonesia, 2016.

Nurfaidah, Sitti. "Three Attitudes of a Reflective Teacher." Research and Innovation in Language Learning 1, no. 1 (2018): 39-48.

Nurfaidah, Sitti, Nenden Sri Lengkanawati, dan Didi Sukyadi. "Levels of Reflection in EFL Preservice Teachers' Teaching Journal." Indonesian Journal of Applied Linguistics 7, No. 1 (2017): 80-92. doi: 10.17509/ijal.v7i1.6861

Reio Jr., Thomas G. "Teacher Emotions and Socialization-Related Learning in the Context of Educational Change". Dalam Christopher Day dan John Chi-Kin Lee (Eds.), New Understandings of Teacher's Work: Emotions and Educational Change. New York: Springer, 2011.

Reio Jr., Thomas G., dan J. Callahan. "Affect, Curiosity, and Socialization-Related Learning: A Path Analysis of Antecedents to Job Performance". Journal of Business and Psychology 18, (2004): 35-50.

Ripski, Michael B., Jennifer LoCasale-Crouch, dan Lauren Decker. "Pre-Service Teachers: Dispositional Traits, Emotional States, and Quality of Teacher-Student Interactions". Teacher Education Quarterly, Spring (2011): 77-96.

Rizka, Fidiya, dan Dewi Rokhanawati. "Hubungan Kesiapan dengan Tingkat Kecemasan Menghadapi Real Teaching pada Mahasiswa DIV Bidan Pendidik Anvullen STIKES Aisyiyah Yogyakarta Tahun 2014." Yogyakarta: STIKES 'Aisyiyah Yogyakarta, 2014. Diakses dari digilib.unisayogya.ac.id pada 31 Maret 2018. 
Al Izzah: Jurnal Hasil-Hasil Penelitian-ISSN: 1978-9726 (p); 2541-0717 (e) Volume 13, Nomor 2 (November, 2018)

Schön, Donald A. Educating the Reflective Practitioner. New York: Basic Books, 1987.

Stahl, Garth, Erica Sharplin, dan Ben Kehrwald. "Developing Pre-service Teachers' Confidence: Real-time Coaching in Teacher Education". Reflective Practice, (2016). doi: $10.1080 / 14623943.2016 .1206882$

Suryana, Ermis. "Analisis Kinerja Mahasiswa Peserta Micro Teaching FITK UIN Raden Fatah Palembang (Studi pada Mahasiswa Program Studi Pendidikan Agama Islam)." Tadrib IV, no. 1 (2018): 120-137.

Tsui, Amy B. M. Understanding Expertise in Teaching: Case Studies of Second Language Teachers. New York: Cambridge University Press, 2003. 